\title{
On the experimental investigation of the rotational coefficients of thermal conductivity
}

\section{Ch. Saret}

To cite this article: Ch. Saret (1894) On the experimental investigation of the rotational coefficients of thermal conductivity, Philosophical Magazine Series 5, 37:226, 338-339, DOI: $10.1080 / 14786449408620552$

To link to this article: http://dx.doi.org/10.1080/14786449408620552

曲 Published online: 08 May 2009.

Submit your article to this journal $\lceil\pi$

Џll Article views: 2

Q View related articles $\widetilde{ }$ 
from which

$$
\sigma=\frac{1}{\mathrm{H}}=\frac{c}{\mathrm{R}} \frac{\mathrm{I}_{m}-\mathrm{I}}{\mathrm{H}_{m}} .
$$

This is Fröblich's formula.

Now this formula holds very well with feebly magnetic bodies; we may from this conclude that in this case the pressure $p$ is correctly valued. On the other hand, it does not agree with strongly magnetic bodies, for which the value of the pressure $p$ is given by the formula of Van der Waals. From the known properties of. this equation, the pressure corresponding to two values of $I$, corresponding to the same susceptibility $K$, is the same.

4. For a fluid, in proportion as the temperature $\mathrm{T}$ decreases the density of the saturated vapour decreases cotemporaneously with the tension; at the temperature at which the density becomes null, the tension is null also. Thus the second part of the equation of Van der Waals vanishes, and we deduce from it the value of the density of the liquid under the pressure null of its saturated vapour.

Applying the same method to the example mentioned above, the parabola cuts the axis of abscissæ at the point $4 \pi \mathrm{K}=516$; the corresponding value of I given by the equation of Van der Waals is $\mathbf{I}=1260$. The direct measurement on the parabola gives 1256 . This is an almost absolute coincidence.

5. From this point the equation of Van der Waals can no longer represent the phenomenon, for the fluid can no longer exist in the liquid state; a change of state takes place, and the representative curve changes suddenly. This is also the case with magnetism ; it is from this point that the curve is no longer parabolie. There is a change of state corresponding to the passage from the liquid to the solid state.

In fine, the phenomena of the magnetization of iron are analogous to those presented by a saturated fluid, and might be calculated by the same formulas; I propose to try if we can find experimentally a reduced equation independent of the magnetized body.

Feebly magnetized bodies are subject to laws analogous to those of liquids at a distance from their point of saturation.-Communicated by the Author, from the Comptes rendus, Jan. 8, 1894.

ON THE EXPERITENTAL INVESTIGATION OF THE ROTATIONAL COEFFICIENTS OF THERMAL CONDUCTIVITY. BY CE. SARET.

In the very amiable and indulgent notice which the Archives de Genève has published of my Eléméns de Orystallographie physique, M. Curie has proposed a method by which the existence 
or absence of rotational coefficients of thermal conductivity in crystals may be ascertained in a simple manner.

I wish here to point out briefly the principle of an analogous method which I was led to try some time ago, and which, as I have subsequently learned, is identical with the method proposed by Boltzmann for the investigation of Hall's phenomenon.

If a point sufficiently distant from the edge of a thin crystallized plate be heated, the isothermal curves obtained by Senarmont's method are ellipses, whatever be the values of the coefficients of rotation.

If instead of working with a continuous plate the plate is split by a straight saw-cut in the direction of a radius from the centre of heating, the isothermal curves will be scarcely modifjed, and will shorten on each side of the slit if the coefficients of rotation are null, but will exhibit a break in the same region if the coefficients are not null. In this case the flow from the centre tends to follow a spiral line; there should be an accumulation of heat on one of the edges of the slit and a falling off on the other.

The experiment may be made still more simply. Instead of sawing the plate it is sufficient to heat a point of the rectilinear edge. If the coefficients of rotation are not zero the isothermal line must undergo a spiral modification, and the distances at which it cuts the edge of the plate on the right and left of the point heated are not equal.

This method is not very certain : it is better to cut the plate by a saw-cut in two halves, which are then adjusted in a suitable support in their original position, leaving a slight interval between the two edges of the slit. By heating a point of this the spiral deformation should be separately produced on each piece, and the isothermal will present discontinuities in the opposite direction at the two points where it meets the slit.

I have tried these various methods on plates of gypsum; in no case have I observed a discontinuity indicating an appreciable spiroidal deformation of the isotherms. I hope to pursue these experiments.

What we have said applies to thin plates perpendicular to the axis of rotation. It will be seen in like manner that on heating by Jannettaz's method a point in a face cut in an unlimited crystal, parallel to the axis of rotation, isotherms should be obtained which are not symmetrical in reference to that diameter which is parallel to this axis. The fact that this deformation has not hitherto been noticed appears to prove that the coefficients of rotation are always zero, or at any rate very small.-Bibliothèque Universelle, No. 4, 1893. 